for the college museum, I am grateful that my liking for natural history brought me in touch with him. It is in the small actions of life that one can best read character. A gentleman to the core, he was never fearful of giving himself away by showing the utmost courtesy to the humblest. An unfastened door or gate, a watertap left trickling he would not abide. Everything at the park must be precision and finish to the smallest details. Over his many acts of private charity he ever kept the veil tightly drawn. A few of them have incidentally come to my knowledge, and they reveal the vastness of his sympathy. His many zoological donations, and his gift to the college of a site on the Menai Straits for a biological station for the study of marine life, bear eloquent testimony to his desire to advance science. May the pile to be raised on this fine site-let us hope at no distant date-be at least one grateful tribute to his memory.

University College, Bangor, November 28.

The Leonid Meteors of 1904.

FROM results of observations of this shower as published in NATURE of November 24 it seems that Leonids were found to be somewhat numerous on the night of November I4. It is to be regretted that those observers who were able to count so many shooting stars on this night had not the following night equally clear, as at Dublin both November I4 and 15 , though not to the same degree, proved favourable for observations, and it was on the latter night that the maximum occurred. Owing to the unsuitable weather that appears to have prevailed in many places on November 15, some details of the observations made on the successive nights of the epoch at the same place may prove interesting.

The night of November 14 turned out ideally fine here, the temperature also being very mild for the season. During a watch on this date from $x$ oh. $15 \mathrm{~m}$. to $13 \mathrm{~h} .45 \mathrm{~m}$. (Dublin time) 16 meteors were counted, of which 7 or 8 were referred to the Leonid radiant. The meteors, especially the Leonids, did not appear very bright, only I of the first and 2 or 3 of the second or third stellar magnitudes having been seen. No particulars of their paths were noted, as doing so might have interfered with the observations of other meteors. Shooting stars were more numerous in the early part of the watch than after midnight, 5 having been counted between $10 h, 45 \mathrm{~m}$. and Irh., of which 2 shot from the direction of Leo. Another, though feebler, maximum occurred about $13 \mathrm{~h}$.; but, as it was considered from the declining meteoric rate that the anticipated miniature shower of this night was already over, observations were discontinued shortly before $14 \mathrm{~h}$.

The night of November is began very inauspiciously; clouds in the early evening covered the heavens, totally concealing both moon and stars. Subsequently, however, the sky partially cleared at intervals, and when observations were begun at 10 . $15 \mathrm{~m}$. passing clouds in the east left clear tracts of considerable area. Though the seeing was thus far from good, yet meteors were considered to be rather scarce, only I shooting star, a third magnitude Taurid, having been seen during a watch extending over nearly an hour. About irh. the clouds passed off, leaving the eastern sky clear until nearly $\mathbf{I} 4 \mathrm{~h}$. Meteors now began to be more numerous. A fine Taurid at $x \mathrm{rh} .25 \mathrm{~m}$. passed down straight towards Leo, which, however, was partly invisible in a bank of fog along the horizon. When about twenty minutes later the "Sickle" emerged clear in the heavens, a succession of fine Leonids left no doubt as to the superior character of the coming display.

From IIh. to $13 \mathrm{~h}$. $30 \mathrm{~m} .32$ meteors were counted; at $14 \mathrm{~h} .55 \mathrm{~m}$, the number had increased to 50 meteors, the total result at $16 \mathrm{~h} .45 \mathrm{~m}$. amounting to $6 \mathrm{o}$ meteors. But owing to clouds observations were greatly hindered from $13 \mathrm{~h} .45 \mathrm{~m}$. to $14 \mathrm{~h}$. $15 \mathrm{~m}$., and a second interruption of nearly equal length, arising from the same cause, occurred about $15 \mathrm{~h}$. During the last hour of the watch the sky was fairly clear, and it was noted that the meteor shower was now rapidly declining. The majority of the meteors were observed to emanate from Leo as soon as the latter had become visible near midnight.

The shower was also observed at the Paris Observatory on the night of November ${ }^{5} 5$ with the following results ${ }^{1}$ :-

1 The results are of course given in Paris mean time.
From roh. $30 \mathrm{~m}$. to 13 h. $15 \mathrm{~m}$. ... 21 meteors observed

" I3h. I5m. , 16h. 30m. ... 29

" 16h. 30m. ", 17h. 35m. ... No shooting star seen

As no mention is made of the state of the weather, it seems the display terminated very abruptly at Paris, slightly more so than in Dublin or elsewhere, as Mr. T. R. Clapham, on November ${ }_{15}$, from ${ }_{15} \mathrm{~h}$. $45 \mathrm{~m}$. to $17 \mathrm{~h}$. $45 \mathrm{~m}$. counted 19. Leonids with 3 three doubtful ones, notwithstanding two brief interruptions from clouds, this result, it may be added, indicating a meteoric rate almost exactly equal to that of the preceding night as given by $\mathrm{Mr}$. Hector Macpherson, who on November 14 , from 15 h. to $18 \mathrm{~h}$., recorded 35 meteors (English Mechanic, November 25, p. 365). The rate on the latter night seems, however, to have been even higher than this to judge from some results, but more observations are, no doubt, desirable.

Dublin, November 29.

JOHN R. HENRY.

\section{Blue-stained Flints.}

Two years ago I found large patches of an intense blue colour, with some black spots, on flints on the quay at Great Yarmouth. I looked for a possible cause, and discovered other patches similar in all respects but colour. The latter patches were black, and had been made by tar spilt by fishermen when tarring their fish skips. I kept some pieces, both black and blue, in a box until some months ago, and no appreciable change had taken place, so I came to the conclusion that the blue colour was produced by the action of the tar on the flint when exposed to sunlight.

This occurrence is interesting in view of the action noticed by Dr. Allen between gas-lime and flint, and points to the action on the flint of some substance common to the tar and gas-lime.

May I suggest to your former correspondent that the blue flints seen at Bournemouth were produced from the black, and not vice vers $\hat{a}$.

County School, Ilford, Essex.

\section{"FIND" OF ROYAL STATUES AT THEBES.}

THE "land of surprises and paradoxes," as Egypt has well been called, has once again justified its reputation, and out of the ruins of one of its most ancient cities there has come to light a mass of historical evidence which, if we mistake not, will be found to be of more importance the more it is studied. It will be remembered that for many years past M. G. Legrain has been carrying out a series of repairs of a very far-reaching character on the mass of buildings of various styles and ages which is commonly known as the "Temple of Karnak." In the course of this work he has collected a number of important facts which, when duly arranged, will be of considerable use to the student of ancient Egyptian architecture, and, side by side with these, he has brought together a considerable amount of information of value historically. It is not our purpose even to outline the broad facts of the works of restoration which he has carried out, and we therefore pass on to state briefly the facts which relate to his last "find" of monuments at Karnak.

Early in the present year M. Legrain was continuing the excavation of a portion of the temple precincts near one of the great walls when he accidentally came upon a large pit or well which, it was evident, had been filled up by the ancient Egyptians. Soon after he began to dig out the well the workmen came upon a layer of statues made of hard stone of various kinds, and when the mud was removed from them many of them were found to be inscribed, Beneath this layer of statues was a layer of earth, and beneath the earth was another layer of statues, and the clearing out of the pit showed that it was filled with layers of statues and earth, arranged alternately. The statues were usually found face downwards, and it thus became 